\title{
eFinite element analysis of stress-related -degrade during drying of Corymbia citriodora and Eucalyptus obliqua
}

\author{
Adam L. Redman \\ 1. School of Mathematical Sciences, Science and Engineering Faculty, Queensland University of Technology \\ (QUT), 2 George Street, GPO Box 2434, Brisbane, Queensland, Australia, 4001. Tel: + 6173138 2259. Fax: + \\ 61731382310 \\ 2. Agri-Science Queensland, Department of Agriculture and Fisheries, Queensland Government. 50 Evans \\ Road, Salisbury, Queensland, Australia, 4107. Tel: +61 7 32774349. Fax: +61 7 38751015. E-mail: \\ adam.redman@daf.qld.gov.au
}

\section{Henri Bailleres}

Agri-Science Queensland, Department of Agriculture and Fisheries, Queensland Government. 50 Evans Road, Salisbury, Queensland, Australia, 4107. Tel: +61 7 32774349. Fax: +61 7 38751015. E-mail: henri.bailleres@daf.qld.gov.au

\section{Benoit P. Gilbert}

Griffith School of Engineering, Griffith University. Parklands Drive, Southport, Queensland, Australia, 4222. Tel: +61 75552 8577. Fax: +61 75552 8065. E-mail: b.gilbert@griffith.edu.au

\section{Elliot J. Carr}

School of Mathematical Sciences, Science and Engineering Faculty, Queensland University of Technology (QUT), 2 George Street, GPO Box 2434, Brisbane, Queensland, Australia, 4001. Tel: + 6173138 6979. Fax: + 6173138 2310. E-mail: elliot.carr@qut.edu.au

Ian W. Turner

1. School of Mathematical Sciences, Science and Engineering Faculty, Queensland University of Technology (QUT), 2 George Street, GPO Box 2434, Brisbane, Queensland, Australia, 4001. Tel: + 6173138 2259. Fax: + 6173138 2310. E-mail: i.turner@qut.edu.au 
2. Australian Research Council Centre of Excellence for Mathematical and Statistical Frontiers (ACEMS),

Queensland University of Technology (QUT), Brisbane, Australia

\section{Patrick Perré}

LGPM, CentraleSupelec, Université Paris-Saclay, Grande Voie des Vignes, 92290 Châtenay-Malabry, France.

Tel: + 33141131 679. Fax: + 33141131163 .E-mail: patrick.perre@centralesupelec.fr 


\section{Abstract}

With the use of experimentsl wood properties and input moisture content field data, we developed a predictive 3D stress-strain finite element analysis (FEA) model allowing us to predict the development of stress related end splitting and surface checking degrade during conventional and vacuum wood drying. Simulations were carried out for two Australian hardwood species, messmate (Eucalyptus obliqua) and spotted gum (Corymbia citriodora) as these species contrast, in terms of wood properties, drying rates and stress degrade susceptibility. The simulations were performed using a 1/8 symmetry model where the full board dimensions are 1,900 $\mathrm{mm}$ long $\mathrm{x}$ $30 \mathrm{~mm}$ thick x $100 \mathrm{~mm}$ wide. Moisture content field data model simulations were utilised in a three-dimensional FEA model by extruding a 2D moisture content field computed in the T-L plane across the radial direction to create a 3D model. Material mechanical properties and shrinkage were calculated in relation to moisture content, over discrete time intervals, using a quasi-static solver. End split failure was investigated at the board end, and surface check failure at the board surface, using a Tsai-Wu failure criterion. Simulations showed that messmate was more susceptible to end splitting than spotted gum and that conventionally dried messmate was more susceptible to surface checking than vacuum dried messmate. The same results were observed from drying trials. The location of predicted surface check failure also matched drying trials and are compared.

\section{Keywords}

Drying stress

Tsai-Wu failure

Drying model

Vacuum drying

Finite element modelling 


\section{Introduction}

Wood drying consists of the removal of water from the wood structure before its intended end use. When freshly sawn, wood contains a large quantity of water, with initial moisture contents of Australian hardwoods ranging from approximately 30 to $120 \%$ (Bootle 2005). If the wood surfaces are left exposed to the atmosphere, the board will naturally dry until it reaches an equilibrium moisture content, which is dependent upon the ambient conditions governed by temperature and relative humidity. The equilibrium moisture content generally varies from between 6 to $16 \%$ depending on the geographic location and the season. Among other properties, dried wood has the advantage over freshly sawn or 'green' wood, of having improved strength properties (i.e. hardness, stiffness, strength), is easier to transport, handle and machine, and in terms of shrinkage and swelling is more stable for end use (Risbrudt et al. 2010). This improved stability comes from the moisture content of the wood equalising to its ambient conditions and subsequently undergoing less fluctuation, which is the cause of wood shrinkage and swelling.

Drying wood outdoors under ambient conditions can be a very slow process, particularly for many hardwood species, taking anywhere up to a year or more, depending on the wood species and/or board thickness. Wood drying kilns are employed to accelerate drying by improving and controlling airflow, temperature, humidity and atmospheric pressure properties. Although the types of kiln used to accelerate wood drying are many and varied, they all have the same objective; to dry wood in the fastest and most economical way possible with minimal drying induced degrade relevant to the product end use. However, due to the complexity of wood drying, these three aims influence each other and one must find a balance to optimize the drying process. Drying time is usually restricted by the desired level of acceptable dried quality (Perré 2007a).

Dried quality includes the variation in final moisture content within single and between multiple wood members, and degrade including residual drying stress, distortion, wood cell collapse deformation (where wood cells actually collapse), and external or internal tearing of wood tissue in the form of splits at the board ends (Fig. 1a) or at the surfaces (AS/NZS:4787 2001), commonly referred to as 'surface checks' (Fig. 1b). Many eucalypt species, particularly those of low density, are prone to collapse deformation, splitting and checking (Innes 1996). Assuming the absence of collapse, no deformation occurs when removing liquid water and drying stresses start due to shrinkage occurring in the hygroscopic domain. When wood dries, its exterior dries more rapidly than the interior to form a moisture content gradient. Once the outer layers dry below the fibre saturation point (FSP), below which wood starts to shrink, and while the interior is still saturated, stresses are generated because the 
shrinkage of the outer layers is restricted by the wet interior. Wood material is strongly orthotropic and inhomogeneous, and stresses and cracks that occur during drying are predominantly caused by orthotropic shrinkage (Perré 2007a). For most species, the shrinkage in the tangential wood direction is generally double that in the radial direction, and the transverse shrinkage is approximately 100 times greater than in the wood longitudinal direction (Risbrudt et al. 2010). Rupture of the wood in the form of splits and checks occur if these stresses across the grain exceed the tensile strength. Checks can also occur internally due to stress reversal. Some species are more prone to certain forms of drying induced degrade than others. Degrade depends on a number of factors that are mostly related to wood structure and composition. The factors influencing these characteristics include growing conditions, plantation stands and presence of reaction wood (Redman et al. 2016).

The successful control of drying defects in a drying process consists of maintaining a balance between the rate of evaporation of moisture from the surface and the rate of outward movement of moisture from the interior of the wood (Perré 2007a); therefore controlling the moisture content (MC) gradient will in turn control the magnitude of drying stresses and subsequent susceptibility to check and split degrade.

Conventional kiln drying with controlled heating, humidity and air-flow under atmospheric pressure conditions is the primary method for drying timber in Australia (Nolan et al. 2003). In recent years, vacuum drying of hardwood timber (particularly in Europe and the USA) has proven in many applications to be a more economical alternative to conventional kiln drying methods, with similar or better quality outcomes (Fernandez-Golfin and Alvarez Noves 1996; Möttönen 2006; Savard et al. 2004). For this reason, the Australian hardwood timber industry invested in a project to establish the viability of vacuum drying technology for drying four high volume commercial Australian hardwood species with respect to drying quality, time and cost. Moreover, it was recognised that a better knowledge of the material and associated drying behaviour is required to fully optimize the vacuum drying process in the future (Perré 2007a).

A component of the project was to develop a hardwood vacuum drying model (Redman et al. 2017) based on previous work conducted for softwood species (Perré 2007b). A two-dimensional, diffusion and permeability based multiphysics heat and mass transfer model was developed by adapting the TransPore model, used to predict the drying behaviour of softwoods, and applying the drying model to Australian hardwood species. TransPore was originally developed by Perré and Turner (1999a; 1999b), and recently had its accuracy and numerical efficiency enhanced by Carr et al. (2013a; 2013b) to include novel strategies such as variable-stepsize Jacobianfree exponential time stepping and a dual-scale modelling approach. 
As described by Redman et al. (2017), a series of vacuum and conventional drying trials were preformed to generate data to validate the heat and mass transfer model using four Australian hardwood species; mature native forest spotted gum (Corymbia citriodora Hook), blackbutt (Eucalyptus pilularis Sm), jarrah (Eucalyptus marginata D.Don ex Sm.), and messmate (Eucalyptus obliqua L’Herit.). The species were specifically chosen based on their large commercial volume, and contrasting drying characteristics and wood properties. For example, spotted gum is known to be the most unproblematic species to dry in terms of resistance to drying degrade and has the highest basic density (BD) of $1000 \mathrm{~kg} / \mathrm{m}^{3}$ (Bootle 2005). Alternatively, messmate is one of Australia's most difficult species to dry due to its propensity to collapse, internal and surface check, and has the lowest BD of $630 \mathrm{~kg} / \mathrm{m}^{3}$ (Bootle 2005).

The experimental method used connected vacuum drying trials to conventional drying trials by using long boards that were sawn in half, where one half was used for vacuum drying trials while the other half was used for conventional drying trials. To select a representative subset of the population, 100 randomly selected boards were chosen to measure wood properties and quality after drying. Dried quality was quantified by measurements of distribution of average MC and MC gradient, and stress related degrade, including surface checking, end splitting, internal checking and collapse. In the current paper we are only interested in stress-related degrade, and the data produced by Redman et al. (2017), expressed as a percentage of degrade existence, from the 100 randomly selected boards, are provided in Table 1 . This data highlights that:

- messmate was prone to all forms of stress related degrade,

- messmate was the only species exhibiting collapse degrade,

- $\quad$ spotted gum had the lowest overall susceptibility to all the combined forms of degrade, and

- $\quad$ vacuum drying, on average across all tested species, induced only about $60 \%$ less surface checking and 80\% less end split type degrade than conventional drying.

The development of the heat and mass transfer model previously presented (Redman et al. 2017; Redman et al. 2012; Redman et al. 2016), described the measurement of a number of wood properties deemed essential for accurate modelling (Perré (2010); Salin (2010)), for the TransPore model input data. The properties measured to achieve accurate modelling results were: wood density, initial MC, fibre saturation point, fibre and vessel porosity,shrinkage, mass diffusivities, desorption isotherm characteristics and gas permeability. 
By using the moisture content gradient outputs derived from the heat and mass transfer model described by Redman et al. (2017)., the basis of this study is to simulate and understand stresses that cause the substantial differences in end splitting and surface check degrade observed between conventional and vacuum drying of messmate and spotted gum species. The two-dimensional, time-dependent moisture gradient outputs are used as input data to create a three-dimensional stress/strain model in the Strand7 software (Strand7 2005), using finite element analysis, a method used previously by Ekevad et. al. (2006) and (2011) to simulate distortion and shrinkage of boards during drying. As three-dimensional moisture gradient fields were not available for this model, some assumptions were made to extend the two-dimensional field into three-dimensions. Additionally, a simplified drying mechanical model is assumed which includes elastic deformation and moisture induced shrinkage and excludes viscoelastic and mechano-sorptive creep. This assumption forces us to focus on the primary phase of drying, when surface checking and end splitting occurs, which is what we want to achieve. Indeed, it is impossible to model stress reversal with this assumption and to subsequently predict stress induced degrade at the end of drying, such as internal checking. With these assumptions in mind, this work is considered as a feasibility study to investigate the concept of simulating stress-related drying degrade and to stimulate further research in this area.

Investigating the hygro-mechanical effects on the behaviour of wood drying, and associated stress related failure, is the primary objective of this research. More specifically, with the use of experimental wood properties and input moisture content field data we aim to develop a predictive 3D stress-strain finite element analysis (FEA) model allowing prediction of the development of stress related end splitting and surface checking degrade during conventional and vacuum wood drying. Two Australian hardwood species were targeted, messmate (Eucalyptus obliqua) and spotted gum (Corymbia citriodora) as these species contrast, in terms of wood properties, drying rates and stress degrade susceptibility.

\section{Materials and methods}

A flow chart of the modelling approach used for this study is provided in Fig. 2. It consists of a four stage sequential process. The first stage involves the use of the TransPore model to generate moisture content field data in the Tangential (T)-Longitudinal (L) plane (thickness $x$ length), which is then extruded across the radial (R) direction of the board (width) to create 3D moisture content fields during drying. The second, third and fourth stages involve the use of the Strand7 model for predicting the elastic and moisture induced shrinkage strains, 
describing the geometric configuration, running the model and analysing the failure criteria. The modelling approach is described in more detail in the following sections.

\section{Heat and mass transfer formulation}

Heat and mass transfer modelling, using TransPore is described in detail by.Redman et al. (2017). For vacuum drying, the external conditions supplied to TransPore were measured directly using kiln conditions from drying trials. At any point in time, the external conditions were vacuum pressure, temperature and relative humidity.

For conventional kiln drying simulations, the external conditions used in the TransPore model were temperature and relative humidity, and the kiln pressure was held constant at atmospheric pressure. The conditions were based on the recommended industry drying schedules for these species were applied in accordance with those outlined in Rosza and Mills (1997).

The kiln drying schedules used are shown in Table 2 and are represented as temperature and relative humidity (RH) change points based on average board moisture content. For the vacuum drying simulations, the vacuum pressure fluctuated between 100 and 200 mbar (as measurement during experiments), and for conventional drying simulations it was held at a constant 1000 mbar. It should be noted that for conventional drying schedules, the temperature and RH set points were instantaneously stepped when the average moisture content change point is reached. This is not the case for vacuum drying schedules where the temperature and RH were 'ramped' between set points, based on the continuous reduction of average moisture content as drying progresses. Redman et al. Redman et al. gum and messmate species.

Wood is an orthotropic material with three directions: radial (R), tangential (T) and longitudinal (L) (Fig. 3a). For all simulations presented in this study (TransPore and Strand7), the board thickness is in the T direction, width the $\mathrm{R}$ direction and length the $\mathrm{L}$ direction, where thickness < width < length. The TransPore model used in this study is limited to two-dimensions and was used to simulate drying in the board tangential (T) and longitudinal (L) directions. This plane was used, as it allows investigation of the evolution of moisture gradients over time at the board ends and wide surfaces, the areas of interest for end splitting and surface checking investigations, and the board thickness is the direction that most drying takes place. Furthermore, during industrial drying, boards are placed in rows such that their sides are touching, substantially limiting drying on the board width direction, and a 
limited moisture gradient is therefore assumed along the R direction in this study. A schematic of the TransPore board model and location of the T-L plane are shown in Fig. 3a.

A triangular structured mesh was constructed. A magnified section of the mesh is shown in Fig. 3b. The T-L plane dimension used was $1900 \mathrm{~mm}$ long x $30 \mathrm{~mm}$ thick, the same dimension of boards used in drying trials described by Redman et al. (2017).

TransPore was used to generate moisture content field data $X_{T, L}^{i}$ in the T-L plane starting at time $\mathrm{t}_{1}=0$ iterating by time steps $t_{i}$ (determined by the TransPore numerical solution procedure) until the final average moisture content of the board reached $12 \%$ at which point the simulation was terminated. The result is a stored series of seventy $\mathcal{X}_{T, L}^{i}$ field data at discrete time intervals $\mathrm{t}_{i}$. Data was generated for spotted gum and messmate species for both vacuum and conventional drying regimes. The initial average MC of spotted gum and messmate measured from drying trials was 32 and 85\% respectively. These are typical initial moisture content values for these species (Innes and Redman 2005).An example of the TransPore model moisture content field visualisation generated for vacuum drying of messmateis provided in Redman et al. (2017).

\section{Geometric configuration}

As stress induced drying degrade occurs in three dimensions (at the board surface, ends and internally) we desired to build a three-dimensional stress/strain FEA model using the two-dimensional TransPore data. To achieve this, the moisture content field $\mathcal{X}_{T, L}^{i}$ generated by TransPore was extruded in the board width direction to form a series of triangular brick elements. More specifically, this quasi three-dimensional model consists of a series of the same T-L moisture content fields $\left(\mathcal{X}_{T, L}^{i}\right)$ using the mesh shown in Fig. 3B, extruded in the $\mathrm{R}$ direction to form the moisture content field $\left(\mathcal{X}_{T, L, R}^{i}\right)$ within the three dimensional mesh shown in Fig. 4b. To reduce computational time, the Strand7 FEA model was built as a 1/8 board symmetry model as shown in Fig. 4a. The T, R, L direction fixed boundary conditions are shown for the three symmetry surfaces. A magnified view of the structure of the three-dimensional Strand7 model used is shown in Fig. 4b.

The Strand7 FEA model requires three sets of input data: the moisture content field data from TransPore, wood material and mechanical property data, and shrinkage coefficient data. Before explaining the procedure used to run the Strand7 FEA program, the mechanical and physical formulations must be defined. 


\section{Mechanical formulation}

As mentioned earlier, when wood dries it loses water first from its surface. The surface shrinks initially but is restrained by the bulk of the wood that is still saturated. Therefore, the strain field generated by moisture content profiles is not geometrically compatible, resulting in the superposition of a strain field related to a stress field. Mårtensson and Svensson (1997) describe the total strain tensor $\boldsymbol{\varepsilon}$ in a board as being comprised of four components:

$$
\varepsilon=\varepsilon^{e}+\varepsilon^{x}+\varepsilon^{m s}+\varepsilon^{c}
$$

where $\boldsymbol{\varepsilon}^{\boldsymbol{e}}$ is the elastic strain, $\boldsymbol{\varepsilon}^{\mathcal{X}}$ is the strain associated with moisture induced free shrinkage, $\boldsymbol{\varepsilon}^{\boldsymbol{m} \boldsymbol{s}}$ is the mechanosorptive strain (the effect due to the interaction between a change in moisture content and an applied stress) and $\boldsymbol{\varepsilon}^{\boldsymbol{c}}$ is the time dependent (viscoelastic) creep strain under load, independent of moisture content but strongly dependent on temperature.

Previous research shows that the non-elastic, stress relieving components of drying stresses, namely viscoelastic and mechano-sorptive creep, are responsible for stress reversal to occur in the latter part of drying, when the average board moisture content is around the FSP (20-30 \%) (Brandao and Perré 1996; Lin and Cloutier 1996; Perré 1996). After stress reversal through a board cross-section, compressive stresses then occur in the outer layers of a board and tensile stresses in the core layers, effectively eliminating the possibility of end splitting and surface checking to occur under these conditions. For this reason, this model includes just the elastic drying stresses and the subsequent stress and failure formation results are analysed between the board initial moisture content and board average FSP conditions (i.e. 24.5\% for spotted gum and 30\% for messmate) when end and surface splitting have occurred. As the analysis ends when the board reaches average FSP, the outer board layers are below FSP which generates the elastic stresses observed.

Consequently, the focus of this work was to observe simulated end split and surface check failure occuring during the primary phase of drying and considering only the elastic and moisture induced shrinkage strains (i.e. equation 1 becomes $\varepsilon=\varepsilon^{e}+\varepsilon^{x}$. By doing so, this work is considered as a feasibility study to investigate the concept of simulating stress-related drying degrade for further research. The effects of excluding the $\varepsilon^{m s}$ and $\varepsilon^{c}$ strain components on the results is further discussed at the end of the paper. 
In the wood orthotropic radial (R), tangential (T) and longitudinal (L) directions with reference to its anatomy, material elastic stress is related to the elastic strain by the generalised Hooke's law (Dahlblom et al. 1996), described by:

$$
\varepsilon^{e}=C \sigma
$$

where

$\boldsymbol{\sigma}=$ stress vector $\boldsymbol{\sigma}=\left[\begin{array}{llllll}\sigma_{L} & \sigma_{T} & \sigma_{R} & \tau_{R T} & \tau_{L T} & \tau_{L R}\end{array}\right]^{T}$

$\boldsymbol{\varepsilon}^{\boldsymbol{e}}=$ elastic strain vector $\boldsymbol{\varepsilon}^{\boldsymbol{e}}=\left[\begin{array}{llllll}\varepsilon_{L} & \varepsilon_{T} & \varepsilon_{R} & \gamma_{R T} & \gamma_{L T} & \gamma_{L R}\end{array}\right]$

$\boldsymbol{C}=$ compliance matrix given by

$$
\mathbf{C}=\left[\begin{array}{cccccc}
\frac{1}{E_{L}} & \frac{-v_{R L}}{E_{R}} & \frac{-v_{T L}}{E_{T}} & 0 & 0 & 0 \\
\frac{-v_{L R}}{E_{L}} & \frac{1}{E_{R}} & \frac{-v_{T R}}{E_{T}} & 0 & 0 & 0 \\
\frac{-v_{L T}}{E_{L}} & \frac{-v_{R T}}{E_{R}} & \frac{1}{E_{T}} & 0 & 0 & 0 \\
0 & 0 & 0 & \frac{1}{G_{R T}} & 0 & 0 \\
0 & 0 & 0 & 0 & \frac{1}{G_{L T}} & 0 \\
0 & 0 & 0 & 0 & 0 & \frac{1}{G_{L R}}
\end{array}\right],
$$

where the material behaviour is described by the following parameters:

$E_{L}, E_{T}, E_{R}=$ Young's moduli

$G_{R T}, G_{L T}, G_{L R}=$ shear moduli

$v_{R T}, v_{L T}, v_{L R}, v_{R L}, v_{L T}, v_{L R}=$ Poisson's ratios; with $v_{R T}=v_{T R} \times \frac{E_{R}}{E_{T}} ; v_{R L}=v_{L R} \times \frac{E_{R}}{E_{L}} ; v_{L T}=v_{L T} \times \frac{E_{T}}{E_{L}}$.

The moisture induced shrinkage strain is dependent on the rate of change of $X_{b}$, where $X_{b}$ represents the bound water content at a point in space and time, and is given by:

$$
\mid \begin{array}{ll}
\varepsilon^{x}=\alpha\left(x_{b}-x_{f s p}\right), & \text { if } x_{b} \leq x_{f s p} \\
\varepsilon^{x}=0, & \text { if } x_{b}>x_{f s p}
\end{array}
$$

where $\boldsymbol{\alpha}$ is defined as:

$$
\boldsymbol{\alpha}=\left[\begin{array}{llllll}
\alpha_{L} & \alpha_{R} & \alpha_{T} & 0 & 0 & 0
\end{array}\right]^{T},
$$


and $\alpha_{L}, \alpha_{R}$ and $\alpha_{T}$ are material shrinkage coefficients of moisture induced strain and $X_{f s p}$ is the saturation point. The shrinkage occurs only with a change of bound water (Skaar 1988), i.e. when $x_{b} \leq x_{f s p}$. The coefficients and saturation points $\mathcal{X}_{f s p}$ used in this study are detailed further in the following section.

\section{Physical formulation}

Material properties were established from the literature for the messmate and spotted gum species and consisted of: (i) the elastic and shear moduli, and Poisson’s ratios required for the elastic strain compliance matrix (eq. 3), (ii) the fibre saturation point $\left(X_{f s p}\right)$, and (iii) the shrinkage coefficients for moisture induced strain (eq. 5).

The mechanical properties are updated in Strand7 related to the moisture content of the element and their value is calculated using the method developed by Guitard and El Amri (1987). Their method is based on a regression analysis of literature data regarding density and moisture content versus Young’s/shear moduli and Poisson's ratios for 45 hardwood species. The air-dried density at $12 \%$ moisture content and $\mathcal{X}_{f s p}$ values for spotted gum and messmate measured by Redman et al. (2011) were used as input parameters (see Table 3) into the Guitard and El Amri (1987) hardwood regression equation. Above $\mathcal{X}_{f s p}$, the Young's and shear modulus values are assumed to be constant (Wang et al. 2002). When $x_{b} \leq \mathcal{X}_{f s p}$, the Young's and shear modulus values are calculated using eq. (6) from Kretschmann (2010) incorporating the values at $12 \%$ moisture content and

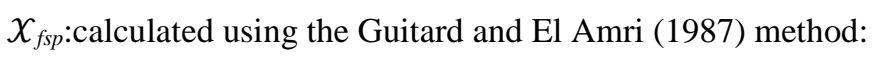

$$
P=P_{12}\left(\frac{P_{12}}{P_{f s p}}\right)^{\left(\frac{12-x_{b}}{x_{f s p^{-12}}}\right)}, \text { when } 0 \leq x_{b} \leq \mathcal{X}_{f s p,}
$$

where $P$ is the modulus value at moisture content $X_{b}, P_{12}$ is the same property at $12 \%$ moisture content, $P_{f s p}$ the same property for green wood at the fibre saturation point $\mathcal{X}_{f s p}$.

The shrinkage values for each species $\left(\alpha_{L}, \alpha_{R}\right.$ and $\left.\alpha_{T}\right)$ expressed as $\%$ strain per $\% x_{b}$ change, used for the moisture induced shrinkage strain calculations (eq. 4) in each wood direction, were derived from Redman et al. (2011). The values for spotted gum are $\alpha_{L}=0.001, \alpha_{R}=0.374$ and $\alpha_{T}=0.385$, and for messmate are $\alpha_{L}=$ $0.001, \alpha_{R}=0.274$ and $\alpha_{T}=0.395$. 


\section{Numerical solution}

The following finite element formulation in Strand7 refers to the model flow chart provided in Fig. 2. The heat transfer module in Strand7 is used to generate the moisture induced shrinkage as the physical equations between the two phenomenon are indentical.

Starting at time $\mathrm{t}=0$ and iterating by time steps $\mathrm{t}_{i}$ the following procedure was performed for each $\mathrm{t}_{i}$ :

- $\quad$ The TransPore moisture content field data $\mathcal{X}_{T, L}^{i}$ is inserted into the Strand7 1/8 symmetry plane model structure at the nodes in the extruded T-L planes (see Geometric conguration above) as a temperature load at the nodes.

- The moisture content of each triangular brick (prism) element is calculated as the average of its nodal moisture content values (6 nodes per brick). The material properties are assigned to each triangular brick element based on eq. (6) and Table 3 and the calculated moisture content of the element.

- The shrinkage coefficients were assigned to each triangular brick element as thermal expansion coefficients. The coefficients are updated at each iteration so shrinkage only occurs following eq. (4) when $\chi_{b} \leq \chi_{f s p}$.

- $\quad$ The Strand7 quasi-static solver is run to follow the evolution of the stress related field during drying. The non-linearity is considered herein by updating the mechanical properties and occurrence of shrinkage below $\mathcal{X}_{f s p}$ in previous steps at each iteration of the quasi-static solver.

- $\quad$ The three-dimensional stress-field data $S_{R, T, L}^{i}$ are then stored at each iteration.

The iteration is completed when the last input moisture content field $\mathcal{X}_{T, L}^{\text {end }}$ is processed.

\section{Tsai-Wu criterion}

Failure theory is a scientific tool for predicting failure of materials under certain loads or stresses. It is mathematically expressed as a failure criterion that varies for different materials. Previous studies by Cabrero et al. (2010) and Mascia and Simoni (2013), investigated a number of different failure criteria for wood and concluded that the Tsai Wu failure criterion is well suited to wood, thanks to its ability to deal with anisotropic media.

As our investigations are interested in board end splitting and surface checking, the Tsai-Wu criterion was applied to the stresses in the board thickness (T) and width (R) directions only. 
The Tsai-Wu criteria is a quadratic, stress-based criterion where failure is deemed to occur when the following condition is satisfied:

$$
A+B+C+D+E+F \geq 1
$$

where the eq. (7) parameters are defined in the radial-tangential directions as (Tsai and Wu 1971):

$$
\begin{aligned}
& A=\frac{\sigma_{T T}^{2}}{\sigma_{T T t}^{u} \sigma_{T T c}^{u}}, \\
& B=\frac{\sigma_{R R}^{2}}{\sigma_{R R t}^{u} \sigma_{R R c}^{u}}, \\
& C=\frac{\tau_{T R}^{2}}{\left(\tau_{T R}^{u}\right)^{2}}, \\
& D=\left(\frac{1}{\sigma_{T T t}^{u}}-\frac{1}{\sigma_{T T c}^{u}}\right) \sigma_{T T}, \\
& E=\left(\frac{1}{\sigma_{R R t}^{u}}-\frac{1}{\sigma_{R R c}^{u}}\right) \sigma_{R R}, \\
& F=\frac{2 F_{T R}^{*} \sigma_{T T} \sigma_{R R}}{\sqrt{\frac{\sigma_{T T t}^{u} \sigma_{T T C}^{u} \sigma_{R R t}^{u} \sigma_{R R c}^{u}}{u}}} .
\end{aligned} .
$$

In eqs. (8-11), the terms $\sigma_{T T}$ and $\sigma_{R R}$ represent the calculated stress in the orthotropic directions $\mathrm{T}$ and $\mathrm{R}$, respectively, and $\sigma_{T T t}^{u}, \sigma_{T T C}^{u}, \sigma_{R R t}^{u}$ and $\sigma_{R R C}^{u}$ represent the ultimate $(u)$ tension $(t)$ and compression $(c)$ stress in the $\mathrm{T}$ and $\mathrm{R}$ directions. The shear strengths in the T-R plane are represented by $\tau_{T R}^{u}$. The $F_{T R}^{*}$ term in eq. (13) is the interaction coefficient and is difficult to determine (Cabrero et al. 2010). Tsai (1992) proposed using the value $F_{T R}^{*}=-0.5$, which corresponds to the generalised Von Misses criterion (Cabrero et al. 2010). Thus, in the wood T-R plane, using the proposed interaction coefficient, the Tsai-Wu failure criteria eqs. (7-13) can then be expressed as:

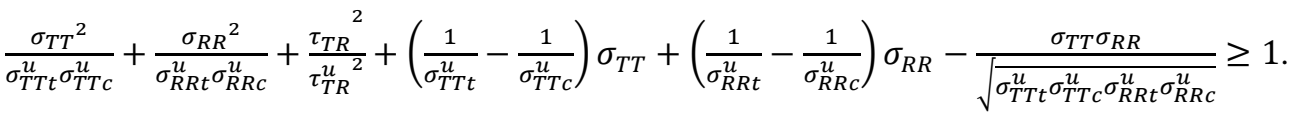

The ultimate radial and tangential tensile and compression stresses, and the ultimate radial/tangential shear stresses were calculated via regression analysis $\left(R^{2}=0.8\right.$ to 0.9$)$ of density versus ultimate stress data measured for 66 hardwood species form literature in Kretschmann (2010), and are presented in Table 4. 


\section{Simulations}

The simulated evolution of the Tsai-Wu failure criteria over time was only investigated at the areas where we experimentally observed end splitting and surface checking in the boards. For end splitting this is at the end of the board and for surface checking this is on the board surface. For end splitting, peak failure was investigated at the end of the modelled board both at the central element and the line of elements through the board thickness, as shown in Fig. 5a. Similarly, the evolution of failure criteria related to surface checking was investigated at the central surface brick of the board and across the width of the board's surface as shown in Fig. 5a.

All of the Tsai-Wu failure criteria results presented use the centroid values of the Strand7 brick elements. The Strand7 software calculates the Tsai-Wu data (eq. 14) at time $t=t_{i}$ using the two-dimensional stress-field data $\mathrm{S}_{R, T}^{i}(i=1$ to $n)$ generated previously and allows it to be visualised.

\section{Results and Discussion}

An example of the evolution of the Tsai-Wu failure criteria for conventionally dried messmate, focusing on the internal central location of the board end, at various stages of reducing moisture content during drying, is shown in Fig.5. Fig. 5a shows a schematic of the board symmetry plane and indicates the location of the observed failure in subsequent images. In this example, the initial average moisture content was $85 \%$. Fig. 5b-f show the evolution of the Tsai-Wu failure at the average board moisture contents of $85 \%$, 40\%, 38\%, 36\% and 33\%. The maximum failure criteria is found to occur first along the centre of the board end, in the width direction, and intensifies as drying progresses, with the centre-face of the board-end peak failure (position of white dot in Fig. 5) occurring when the average board moisture content reaches 38\% (Fig. 5d). The location of the simulated failure criteria indicates that end split failure is likely to occur anywhere along the width of the board, however experimental observations showed that end splitting occurred mainly at mid-width of the board end as shown in Fig. 1a.

The difference between the locations of simulated versus observed end split failure is likely an effect of using the same two-dimensional T-L cross-sectional moisture content profiles along the board width direction (R). Similarly, the large red failure zone at the board edge is also likely due to the expansion of the 2-dimensional MC field to 3 dimensions. Excluding the moisture gradient in this direction reduces the simulated anisotropic stress field at the corners and edges of the board, which may result in an under prediction of the location of end split at the board end. 
The Tsai-Wu failure criteria, plotted against the reduction of average moisture content during drying, at the boardend centre-node (white dot Fig. 5a), for conventional and vacuum dried messmate and spotted gum, is shown in Fig. 6a. The vacuum and conventional drying temperatures for messmate are also shown. The results indicate that the maximum Tsai-Wu failure for messmate conventional drying (4.5) is approximately 4 times higher than messmate vacuum drying (1.3), 4 times higher than spotted gum conventional drying (1.2) and 4 times higher than spotted gum vacuum drying (1.1). These results appear to be consistent with the magnitude of end splitting observed in drying trials reported by Redman et al. (2011). The observed percentage of end split failure (Table 1) for messmate conventional drying (77\%) was comparably 8 times higher than messmate vacuum drying (10\%), 7 times higher than spotted gum conventional drying (11\%) and 10 times higher than spotted gum vacuum drying (7\%). The high susceptibility for conventionally dried messmate to end-split during drying compared to vacuum drying and both forms of spotted gum drying, was both predicted by the model and observed during the trials.

The extent of end splitting and surface checking may be exacerbated by the drying schedule itself. Observation of the Tsai-Wu failure plot for conventional drying of messmate shows a sharp step in the curve. This is directly related to the first temperature step in the drying schedule as shown by the corresponding conventional drying temperature plot (Fig. 6a). This sharp step is not present on the messmate vacuum drying curve, which corresponds to the constant vacuum drying temperature plot. In this case, the temporal evolution of the Tsai criterion is much smoother, with a maximum value at ca. 55\% of averaged MC: this evolution is therefore likely to be due to internal transfer in the board rather than to an artefact produced by a sudden evolution of the kiln conditions. An important observation is that using a smoother ramped approach for conventional drying schedules should be considered by industry.

Fig. 6b shows the Tsai-Wu failure in the board thickness direction, at the centre of the board-end (red line as shown in Fig. 5a), when maximum failure occurs. For messmate, maximum failure occurred when the average board moisture content reached 38\% for conventional drying, and 56\% for vacuum drying. For spotted gum, maximum failure occurred when the average board moisture content reached $24.5 \%$ for vacuum drying and $26 \%$ for conventional drying, from initial average moisture content to FSP (24.5\%). The results are mirrored to show the full board thickness and display a substantially steeper gradient of Tsai-Wu failure for messmate conventional drying compared to the other drying scenarios. As drying stress gradients align with moisture content gradients it seems that the overpressure produced by vacuum drying (Redman et al. 2017Redman et al. 2017) contributes to a flatter moisture content/stress gradient at the end of the board with less susceptibility to end splitting. 
The evolution of the Tsai-Wu failure criteria for conventionally dried messmate, viewed from the centre of the board surface, at various stages of reducing moisture content during drying is shown in Fig. 7. Fig. 7a shows a schematic of the board symmetry plane and indicates the location of observed failure in subsequent images. Figures 7b-f show the evolution of Tsai-Wu failure at average board moisture contents of $85 \%$, 69\%, 39\%, 34\% and $32 \%$. Tensile failure is shown to begin across most of the board surface (except the outer edge) and then intensify as drying progresses. The peak failure occurs at the board surface when the moisture content reaches 39\% (Fig. 7d). The magnitude of failure is similar across the board surface indicating that surface checking is likely to occur anywhere across the surface as drying progresses. Indeed, for a wide board the presence of one single check is not able to relax the stress field over the entire width. Several checks will therefore form along the width, except very close to the edge, when the stress field is smaller for geometrical reasons. This matches the positions of surface checking failure observed from drying trials where surface checking occurred at various locations across the full surface of the board as shown in Fig. $1 \mathrm{~b}$.

The Tsai-Wu failure, plotted against the reduction of average moisture content during drying, at the centre of the surface of the board, for conventional and vacuum dried messmate and spotted gum, is shown in Fig. 8a. The results indicate that the maximum Tsai-Wu failure for messmate conventional drying (2.5) is 2.5 times higher than messmate vacuum drying (1.0), 4 times higher than spotted gum conventional drying (0.6), and 3 times higher than spotted gum vacuum drying (0.9). The observed percentage of surface checking failure (Table 1) for messmate conventional drying (29\%) was 5 times higher than messmate vacuum drying (10\%), 2 times higher than spotted gum conventional drying (11\%) and 2 times higher than spotted gum vacuum drying (7\%). The high susceptibility for conventionally dried messmate to surface checking during drying compared to the other drying regimes was both predicted by the model and observed during the trials. The Tsai-Wu failure curve for messmate conventional drying depicts an earlier lower magnitude peak that appears when the average moisture content reaches $69 \%$. The second failure peak aligns with the sharp step in temperature and could potentially be reduced by implementing ramped changes in scheduled temperature.

Fig. 8b shows the Tsai-Wu failure in the board width direction, at the centre-surface of the board (red line as shown in Fig. 5a), at the point in time when maximum failure occurs. The results display a similar failure profile for each species and drying regime, but with different magnitudes as described above. Simulations predicted the high chance of surface checking occurring for conventionally dried messmate, but not for vacuum dried messmate or conventional and vacuum dried spotted gum, as observed from the drying trials presented in Table 1. 
An example of normal stresses in the board width $\left(\sigma_{R R}\right)$ and thickness $\left(\sigma_{T T}\right)$ directions and shear stress in the width/thickness $\left(\tau_{T R}\right)$ direction versus average board MC, for conventionally dried messmate, is provided in Fig. 8c at the board-end centre-node (white dot Fig. 5a) and Fig. 8d viewed from the centre of the board surface. These stresses are used to determine the Tsai-Wu failure (eq. 14) and the associated Tsai-Wu failure plots are also shown; the same as those plotted in Fig. 6a and 8a. In addition, the grey lines represent the ultimate tensile failure (as presented in Table 4$)$ in the tangential direction $\left(\sigma_{T T t}^{u}\right)$ at the board end (a), and radial direction $\left(\sigma_{R R t}^{u}\right)$ at the board surface (b). Fig. 8c indicates that stress in the thickness direction $\left(\sigma_{T T}\right)$ is the predominant cause of end splitting as it is the only stress that exceeds the ultimate tensile stress in that direction $\sigma_{T T t}^{u}$, and also coincides with the Tsai-wu failure plot. This material direction mode of failure was not observed during drying trials where boards tend to split in the board width (R) direction as shown in Fig. 1a. Again, the difference between the locations of simulated versus observed end split failure is a consequence of using the same two-dimensional T-L crosssectional moisture content profiles along the board width direction (R) as previously mentioned from the observed Tsai-Wu failure trends.

Fig. 8d shows the stress in the board width direction $\left(\sigma_{R R}\right)$ is the predominant cause of surface checking, exceeding the untlimate tensile stress $\sigma_{R R t}^{u}$ during the early, high moisture content, drying phase. This coincides with the Tsai-Wu failure results and the material direction mode of failure observed during drying trials (Fig. 1b).

As a final comment, inclusion of the viscoelastic creep and mechano-sorptive stress components in the FEA model is likely to contribute to an enhanced model and could explain why, for some drying scenarios, the failure criteria was significantly greater than the value of 1 ; the Tsai-Wu failure criteria threshold. By not including the mechanosorptive stress in this model, simulations are likely to overestimate the stresses on the wood because the mechanosorptive creep relax, or reduce, the stresses during drying by up to $40 \%$ or more of the total stress (Haque 2002). This effect, together with the viscoelastic creep, is also the main phenomenon able to explain stress reversal at the end of drying (Perré and Passard 2004; Rémond et al. 2007). The work presented here is relevant in that it demonstrates the potential of the approach to understand observed trends to further optimise the drying process while providing a platform for further refinement. 


\section{Conclusions}

A predictive three-dimensional stress-strain FEA drying model, using measured and empirical wood properties combined with moisture gradient input data, was presented.

The model was able to reproduce the observed surface checking failure magnitude and location trends for vacuum and conventional drying of the two selected species, spotted gum and messmate. The model predicted that conventionally dried messmate was more susceptible to end splitting and surface checking than vacuum dried messmate. Maximum surface checking failure was predicted to occur across most of the surface of the board; a position of failure commonly observed in the drying trials.

The Tsai-Wu failure criteria was unable to precisely predict the localised position of end splitting observed in drying trials, which may be a result of using two-dimensional T-L cross-sectional moisture content profile input data to build a three dimensional FEA model.

The sharp changes in temperature and humidity set points used during conventional drying also translated into sharp spikes in stresses during drying. The same result was not observed for the smoother ramped schedules used in vacuum drying.

The FEA model shows the potential to predict the onset, location (at least for surface cheking) and magnitude of stress-related drying degrade. We recommend further work to refine the model using a completely threedimensional heat and mass transfer model to facilitate a more representative three-dimensional stress FEA drying model, including viscoelastic creep and mechano-sorptive stresses.

This work contributes to a greater understanding of stress degrade formation in hardwoods during drying and may be used in future work to optimise wood drying by reducing drying times and limiting degrade. If one can accurately predict degrade during drying, then it is possible to simulate optimal drying schedules based on degrade limitations. 


\section{Acknowledgements}

The substantial contributions of CentraleSupelec, Université Paris-Saclay, Queensland University of Technology (QUT), Griffith University, Forest and Wood Products Australia (FWPA) and the Queensland Government Department of Agriculture and Fisheries (DAF), to the successful undertaking of this collaborative project are gratefully acknowledged. Authors Turner and Carr wish to acknowledge that this research was partially supported by the Australian Research Council (ARC) via the Discovery Project DP150103675 and DECRA project DE150101137 respectively. 


\section{References}

AS/NZS:4787 (2001) Timber -Assessment of Drying Quality. Standards Australia, www.standards.com.au Bootle KR (2005) Wood in Australia - Types, properties and uses. 2 edn. McGraw Hill, Sydney

Brandao A, Perré P The "Flying Wood" - A quick test to characterise the drying behaviour of tropical woods. In: 5th International IUFRO Wood Drying Conference, Quebec, Canada, 1996. pp 315-321

Cabrero JM, Kifle G, Gebremedhin G (2010) Evaluation of failure criteria in wood members. Paper presented at the 11th World Conference on Timber Engineering 2010 (WCTE 2010), Trentino, Italy,

Dahlblom O, Ormarsson S, Petersson H (1996) Simulation of wood deformation processes in drying and other types of environmental loading* Ann For Sci 53:857-866

Davind J, Ekevad M (2006) Local water vapor diffusion coefficient when drying Norway spruce sapwood Journal of Wood Science 52:195-201

Ekevad M, Lundgren N, Flodin J (2011) Drying shrinkage of sawn timber of Norway spruce (Picea abies): Industrial measurements and finite element simulations Wood Material Science \& Engineering 6:41-48 doi:10.1080/17480272.2010.523121

Fernandez-Golfin JI, Alvarez Noves H Kiln and Continuous Vacuum Drying of Eucalyptus Globulus, Oak and Chestnut 27 and 50mm Thick Boards. In: 5th International IUFRO Wood Drying Conference, Quebec City, Canada, 1996. pp 185-190

Guitard D, El Amri F (1987) Modèles prévisionnels de comportement élastique tridimensionnel pour les bois feuillus et les bois résineux Ann For Sci 44:335-358

Haque MN (2002) Modelling of solar kilns and the development of an optimised schedule for drying hardwood timber. University of Sydney

Innes T, Redman AL (2005) Improvement of hardwood drying schedules. www.fwpa.com.au

Innes TC (1996) Collapse and internal checking in the latewood of Eucalyptus regnans F. Muell. Wood Science and Technology 30:373-383 doi:10.1007/bf00244434

Kretschmann DE (2010) Mechanical properties of wood. In: Agriculture USDo (ed) Wood handbook - Wood as an engineerning material. Forest Products Laboratory, USDA,

Lin J, Cloutier A Finite Element Modelling of the Viscoelastic Behaviour of Wood During Drying. In: 5th Int. IUFRO Wood Drying Conference, Quebec, Canada, 1996. pp 117-122

Mårtensson A, Svensson S (1997) Stress-strain relationship of drying wood. Part1: Development of a constitutive model Holzforschung 51:472-478

Mascia NT, Simoni RA (2013) Analysis of failure criteria applied to wood Engineering Failure Analysis 35:703-712

Möttönen V (2006) Varition in Drying Behaviour and Final Moisture Content of Wood during Conventional Low Temperature Drying and Vacuum Drying of Betula pendula Timber Drying Technology 24:14051413

Nolan G, Innes TC, Redman AL, McGavin R (2003) Australian hardwood drying best practice manual. Forest and Wood Products Research and Development Corporation, www.fwpa.com.au

Perré P The Numerical Modelling of Physical and Mechanical Phenomena Involved in Wood Drying: an Excellent Tool for Assisting with the Study of New Processes. In: 5th Int. IUFRO Wood Drying Conference, Quebec, Canada, 1996. pp 11-38

Perré P (2007a) Fundamentals of Wood Drying. A.R.BO.LOR., Nancy, France.

Perré P (2007b) Multiscale aspects of heat and mass transfer during drying Transport in Porous Media 66:59-76

Perré P (2010) Multiscale modeling of drying as a powerful extension of the macroscopic approach: Application to solid wood and biomass processing. Drying Technology 28:944-959 doi:10.1080/07373937.2010.497079

Perré P, Passard J (2004) A physical and mechanical model able to predict the stress field in wood over a wide range of drying conditions. Drying Technology 22:24-44

Perré P, Turner IW (1999a) A 3-D version of TransPore: a comprehensive heat and mass transfer computational model for simulating the drying of porous media Int $\mathrm{J}$ of Heat and Mass Transfer 42:4501-4521 doi:10.1016/s0017-9310(99)00098-8

Perré P, Turner IW (1999b) Transpore: A generic heat and mass transfer computational model for understanding and visualising the drying of porous media Drying Technology 17:1273-1289 doi:10.1080/07373939908917614

Redman AL, Bailleres H, Perré P (2011) Characterization of viscoelastic, shrinkage and transverse anatomy properties of four Australian hardwood species Wood Material Science \& Engineering 6:95-104 doi:10.1080/17480272.2010.535014

Redman AL, Bailleres H, Perré P, Carr E, Turner I (2017) A relevant and robust vacuum-drying model applied to hardwoods Wood Science and Technology 51:701-719 doi:10.1007/s00226-017-0908-7 
Redman AL, Bailleres H, Turner I, Perré P (2012) Mass transfer properties (permeability and mass diffusivity) of four Australian hardwood species BioResources 7:3410-3424

Redman AL, Bailleres H, Turner I, Perré P (2016) Characterisation of wood-water relationships and transverse anatomy and thier relationship to drying degrade. Wood Science and Technology 50:739-757

Rémond R, Passard J, Perré P (2007) The effect of temperature and moisture content on the mechanical behaviour of wood: a comprehensive model applied to drying and bending. European Journal of Mechanics A/Solids 26:558-572

Risbrudt CD, Ritter MA, Wegner TH (2010) Wood handbook - Wood as an engineering material. Centennial Edition edn. U.S. Department of Agriculture, Forest Service, Forest Products Laboratory, Madison, WI

Rozsa A, Mills RG (1997) Index of kiln seasoning schedules. In: Waterson GC (ed) Australian Timber Seasoning Manual. Third edn. Australian Furniture Research and Development Institute, Launceston, pp 167-175

Salin JG (2010) Problems and solutions in wood drying modelling: history and future Wood Material Science and Engineering 5:123-134

Savard M, Lavoie V, Trembala C Technical and Economical Assessment of Superheated Steam Vacuum Drying of Northern Red Oak. In: N.A.G.R.E.F. COST E15 Conference, Athens, Greece, 22-24 April 2004. Forintek Canada Corp., pp 1-10

Skaar C (1988) Wood-water relations. Springer-Verlag, Berlin. doi:10.1007/978-3-642-73683-4

Strand7 (2005) Theoretical Manual - Theoretical background to the Strand7 finite element analysis system. vol 1. Strand7, Suite 1, Level 5, 65 York Street Sydney NSW 2000 Australia

Tsai SW (1992) Theory of Composites Design. Think Composites,

Tsai SW, Wu EM (1971) A General Theory of Strength for Anisotropic Materials Journal of Composite Materials 5:58-80 doi:10.1177/002199837100500106

Wang SJ, Chui CM, Lin CJ (2002) Variations in ultrasonic wave velocity and dynamic Young's modulus with moisture contnet for Taiwana plantation lumber Wood and Fiber Science 34:370-381 


\section{FIGURES}
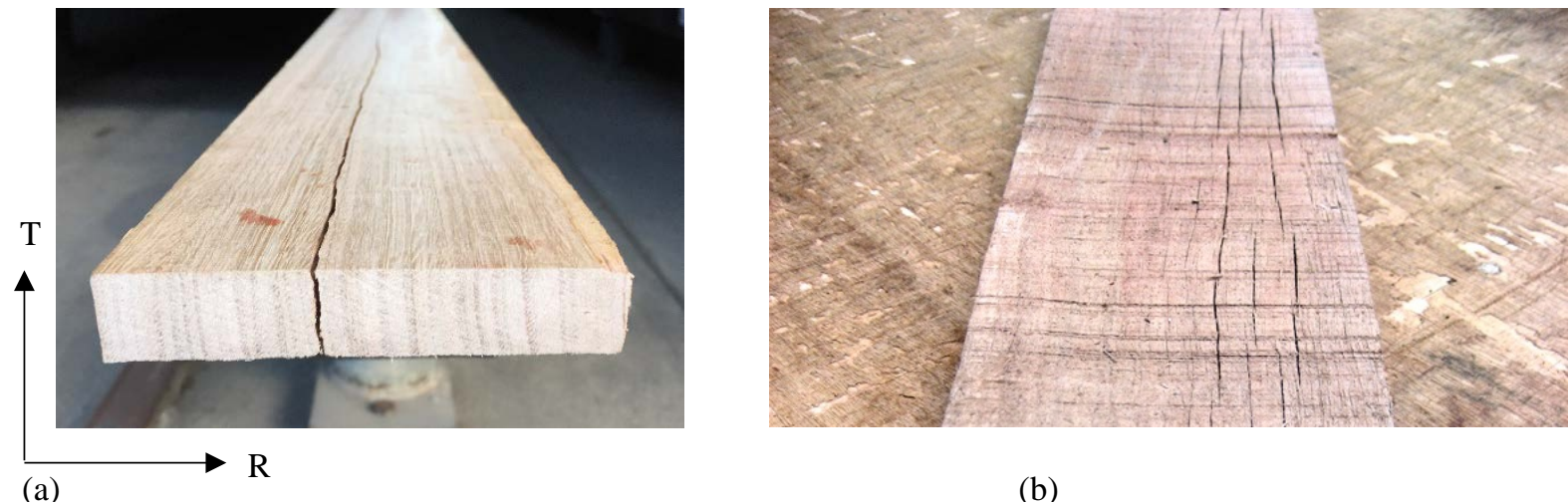

(a)

Fig1. Examples of end split (a) and surface checking (b) stress-induced drying-degrade of messmate boards 


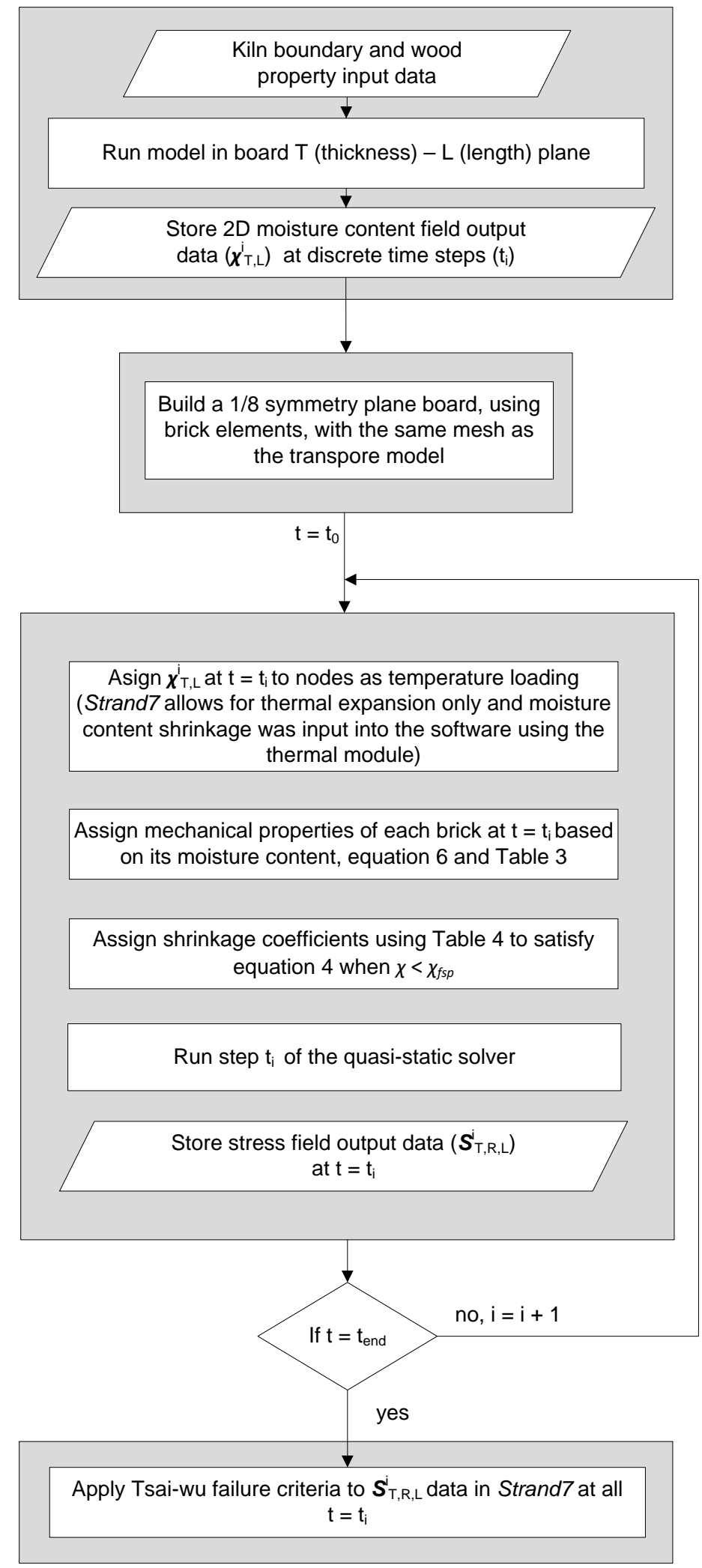

Stage 1

Run TransPore model

\section{Stage 2 \\ Build Strand7 model}

Stage 3

Run Strand7 model

Stage 4

Apply Tsai-wu failure criteria

Fig 2. Flow chart of TransPore and Strand7 FEA modelling approach used. 


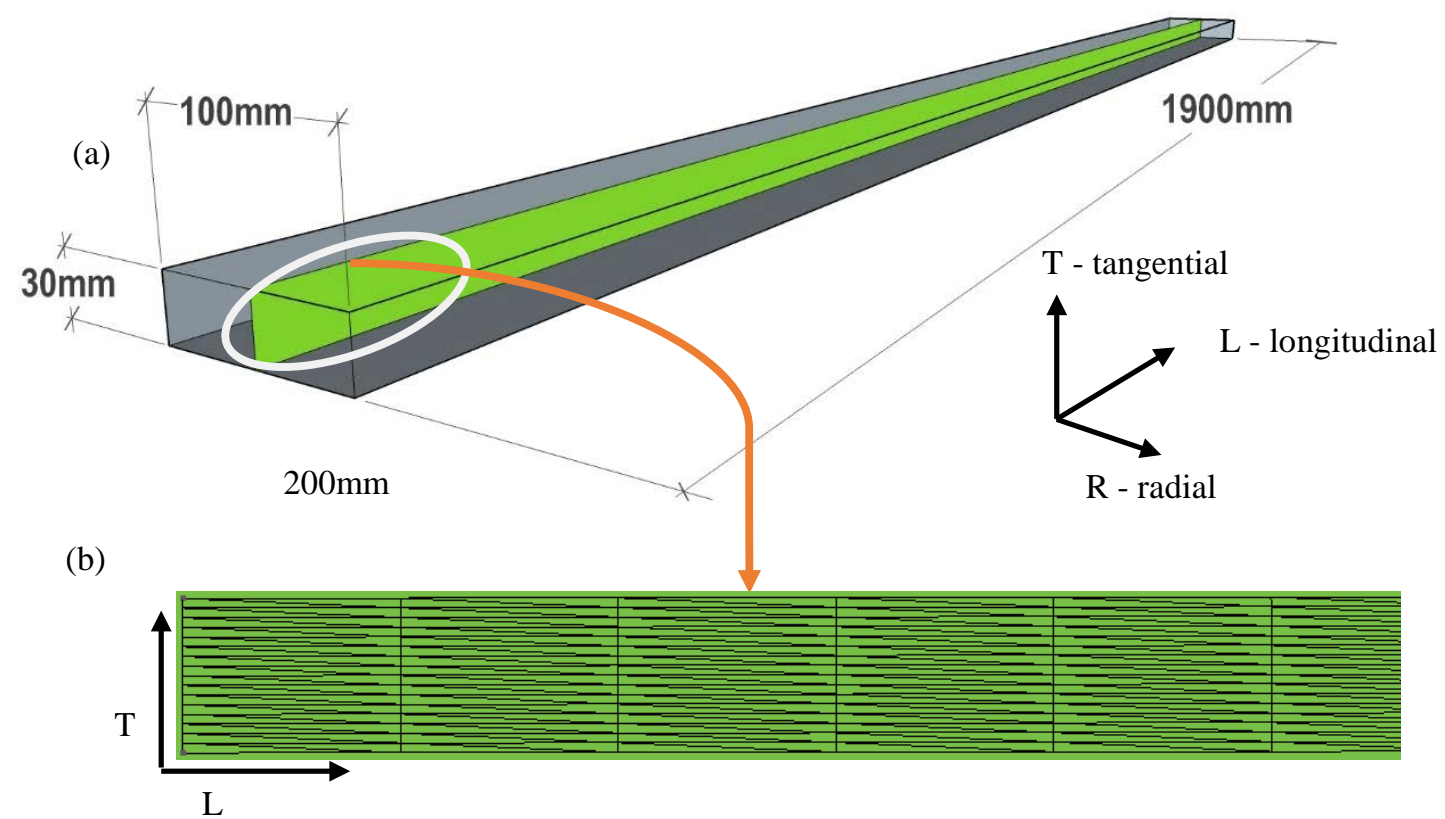

Fig 3. Schematic of board (a) showing the position of the tangential (T) - longitudinal (L) mesh and magnified section of the mesh (b) used for the TransPore model. 


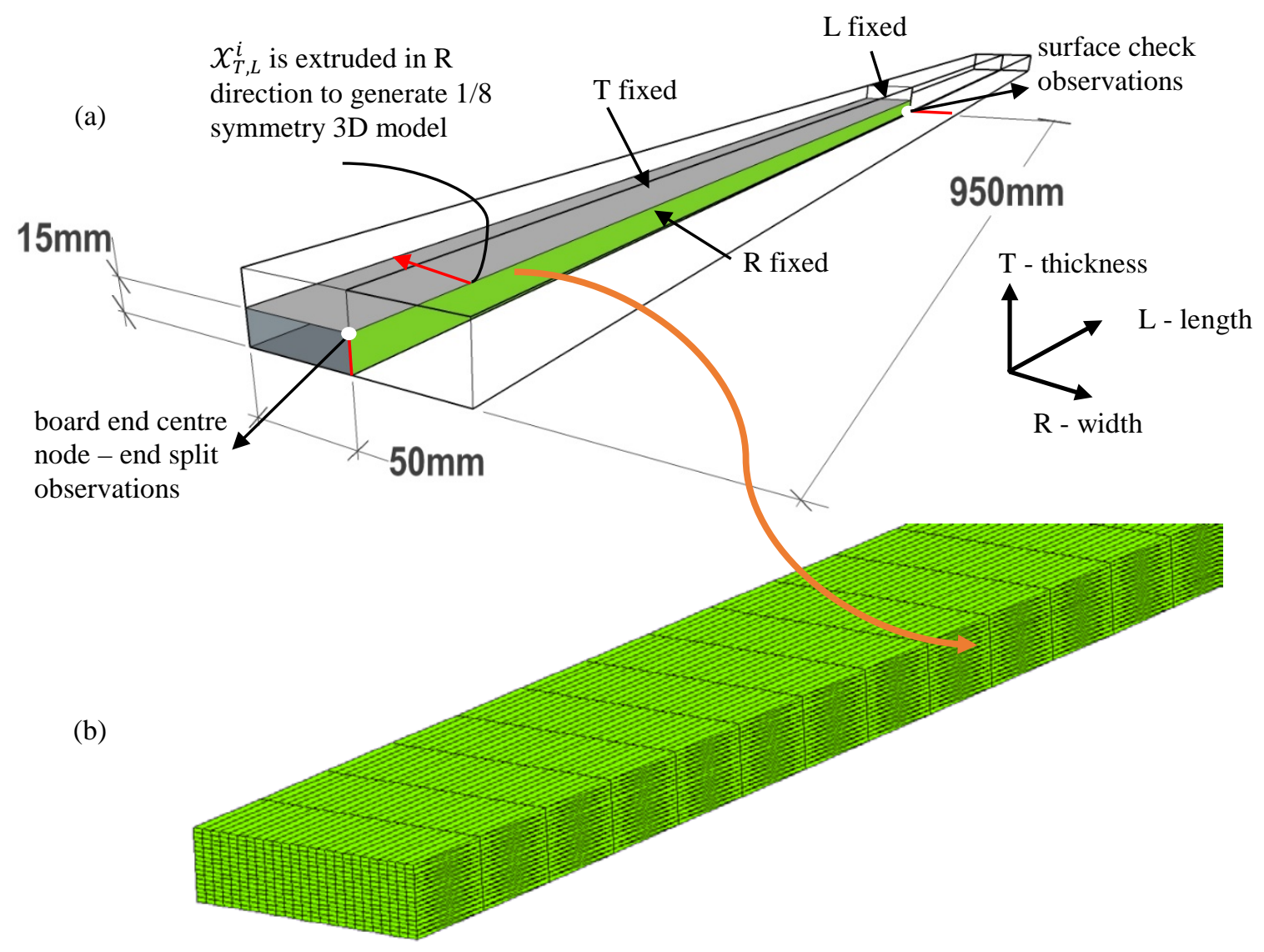

Fig 4. Strand7 FEA model structure build, showing the TransPore moisture field $\boldsymbol{X}_{\boldsymbol{T}, \boldsymbol{L}}^{\boldsymbol{i}}$ (a) which is extruded in the width direction and reduced to a $1 / 8$ symmetry model to produce a 3D model of triangular brick elements as shown in the magnified section (b). The T, R, L fixed boundary conditions are shown for the three symmetry surfaces (a). The points of observation for end splitting and surface checking are shown also. 


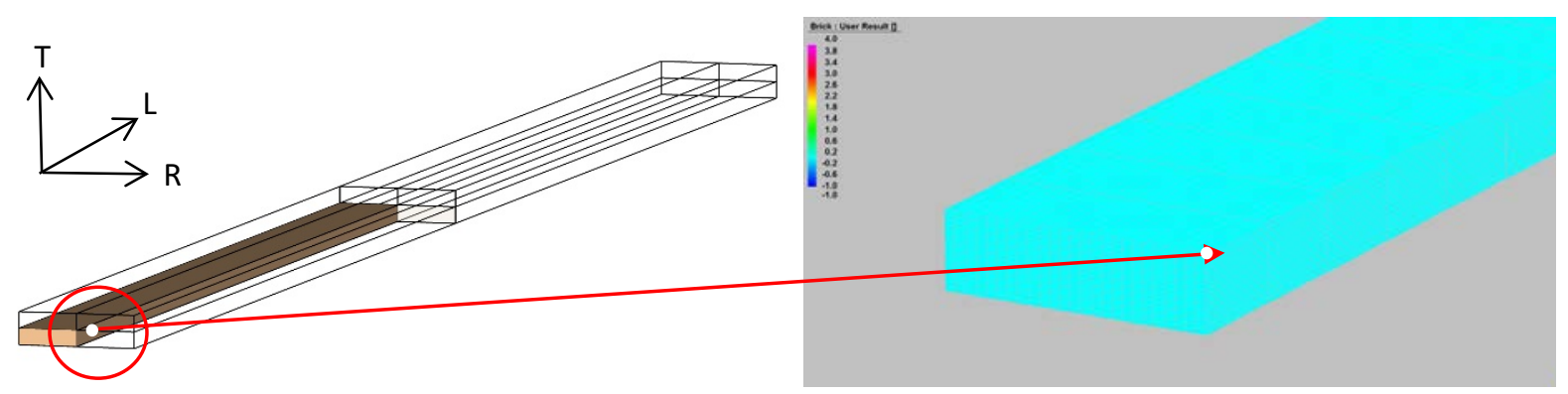

(a)

(b) $85 \%$



(c) $40 \%$
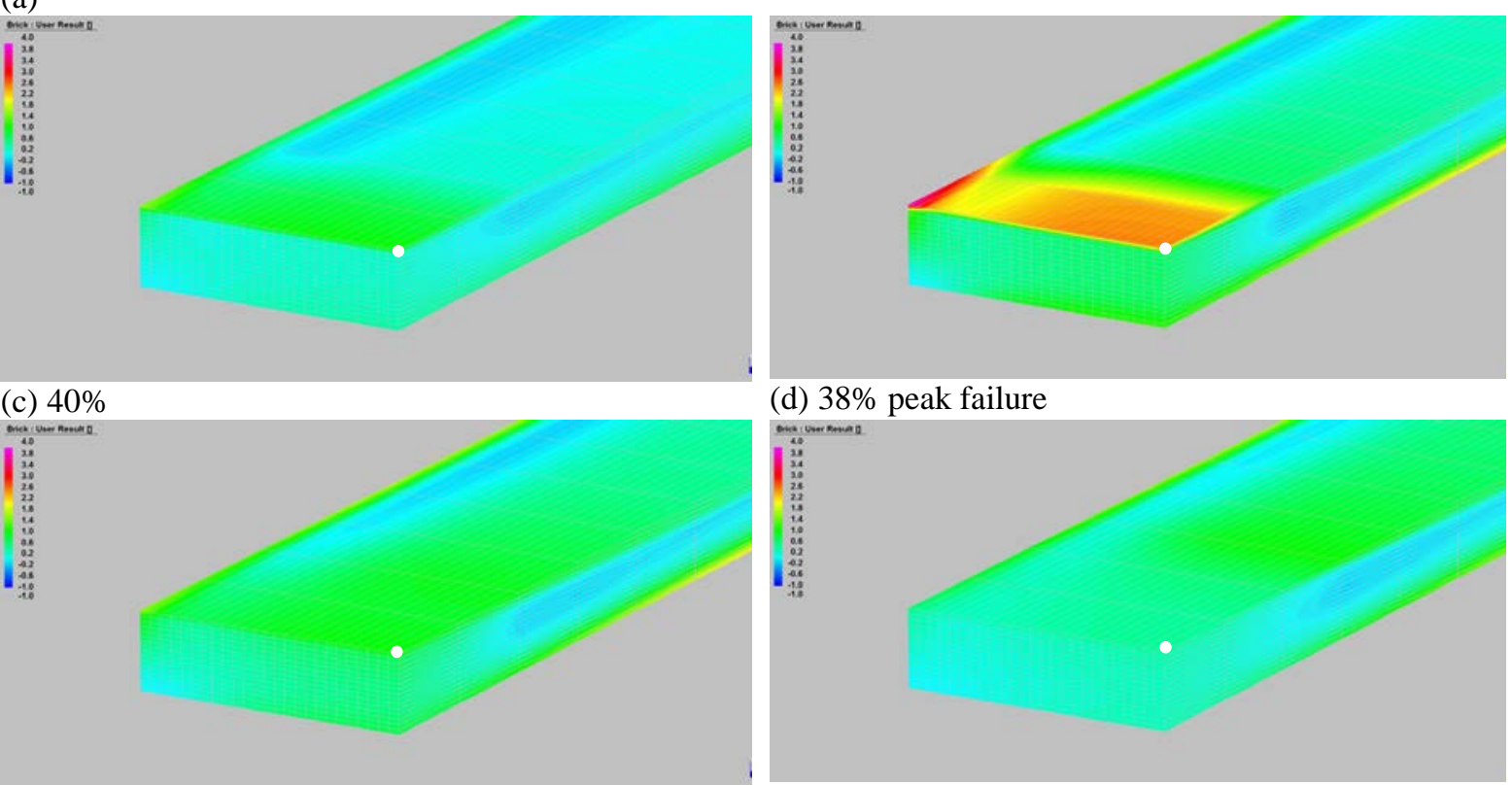

\section{(d) $38 \%$ peak failure}

(e)36\%

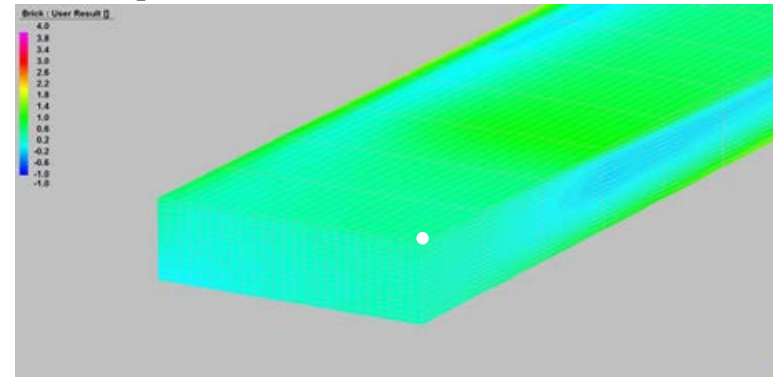

Fig 5. Evolution of Tsai-Wu failure at the board end $1 / 8^{\text {th }}$ symmetry model (a), for conventionally dried messmate, at average board moisture contents $85 \%$ (b), $40 \%$ (c), 38\% peak failure (d), 36\% (e) and 32\%. The white dot represents the centre of the board end-face. 


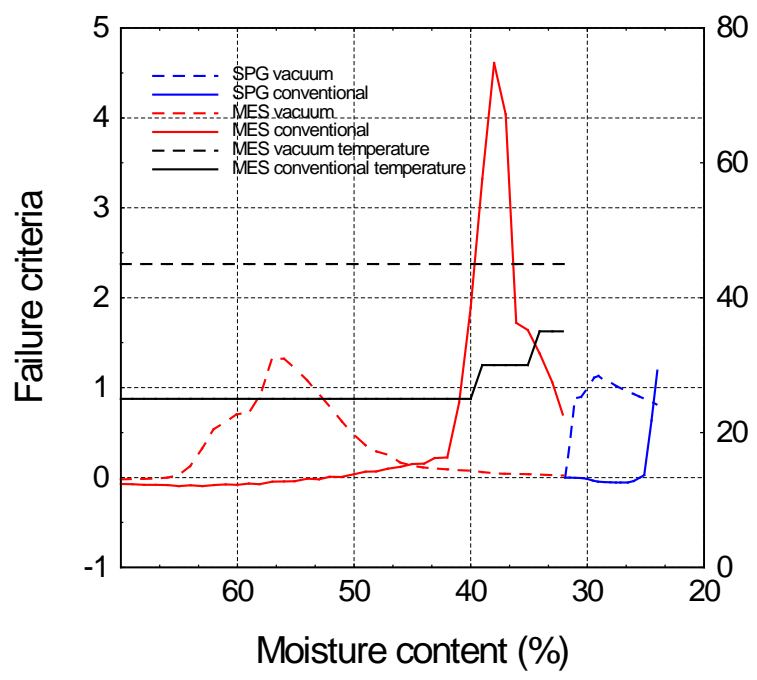

(a)

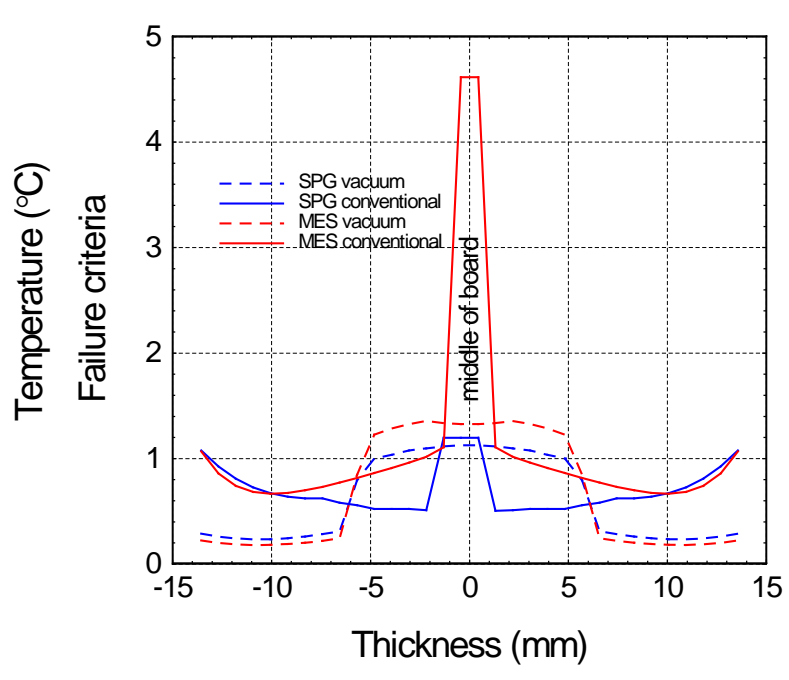

(b)

Fig 6. Tsai-Wu board end-split failure criteria versus moisture content during conventional and vacuum drying spotted gum and messmate, showing drying temperature for messmate (a). Tsai-Wu board end-split failure criteria profile in the thickness direction at peak failure (b). MES = messmate, SPG = spotted gum species 


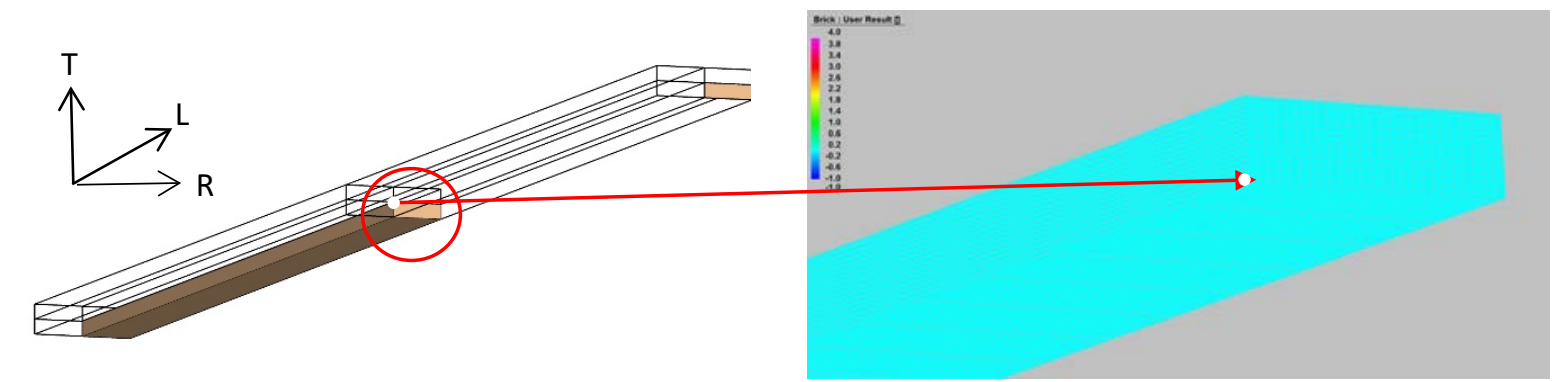

(a)

(b) $85 \%$
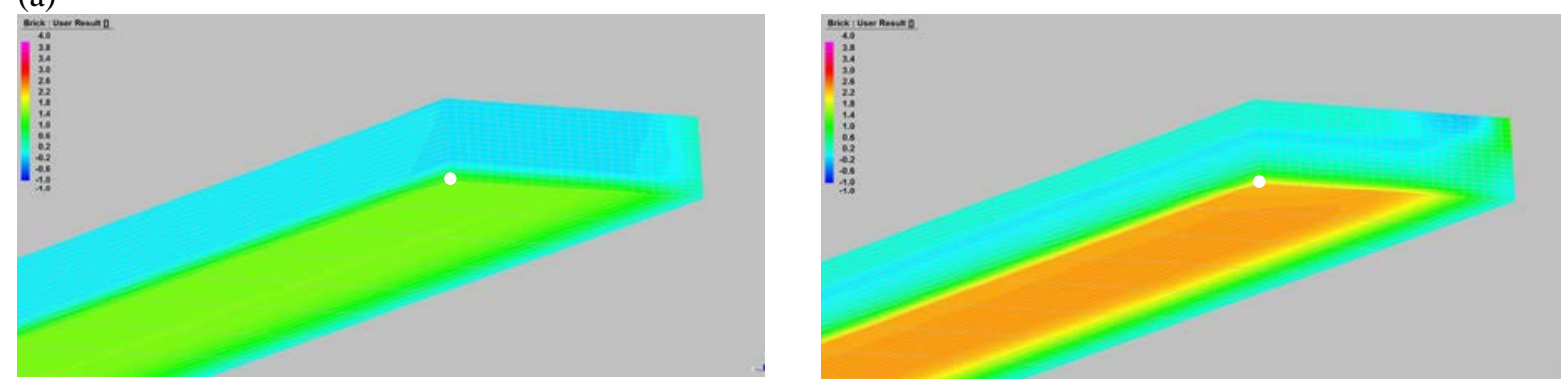

(c) $69 \%$

(d) $39 \%$ peak failure
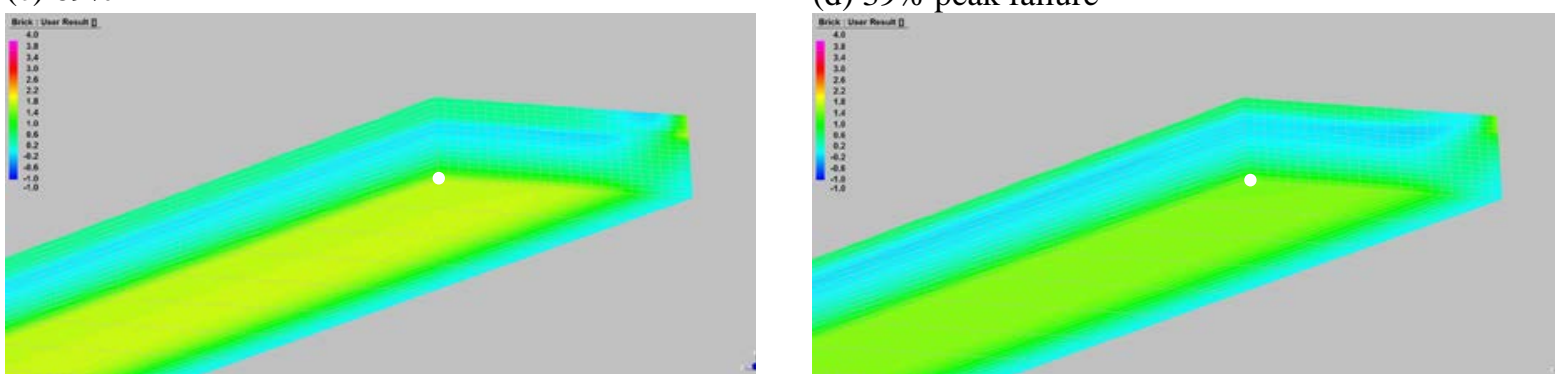

(e) $34 \%$

(f) $32 \%$

Fig 7. Evolution of Tsai-Wu failure at the board surface, $1 / 8^{\text {th }}$ symmetry model looking at the board-midsection (a), for conventionally dried messmate, at average board moisture contents $85 \%$ (b), $69 \%$ (c), 39\% peak failure 2 (d), 34\% (e), 32\% (f). The white dot represents the centre of the board surface. 


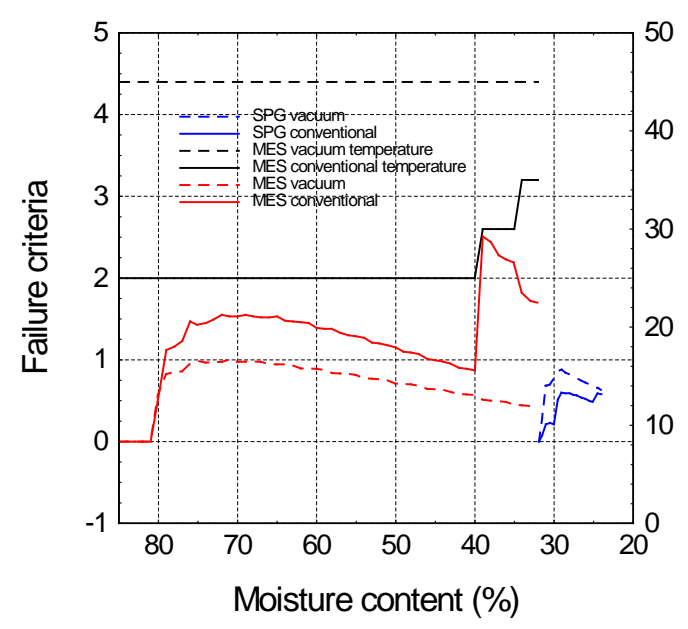

(a)

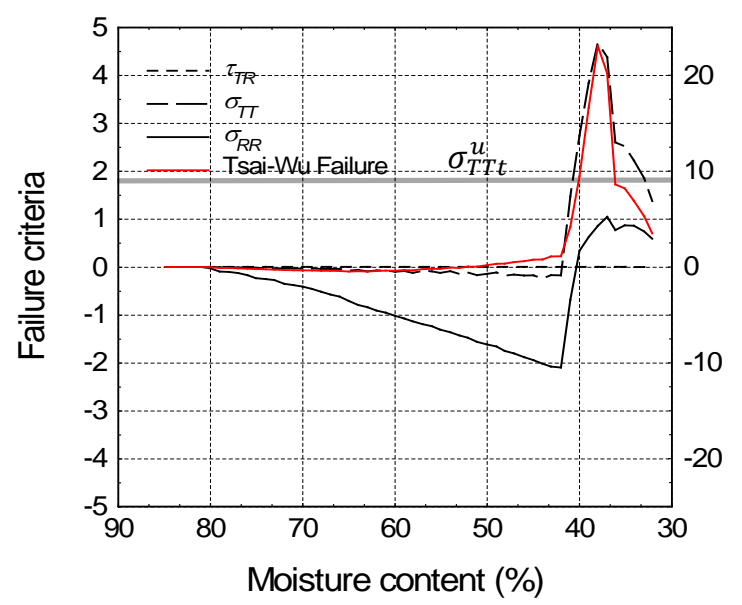

(c)

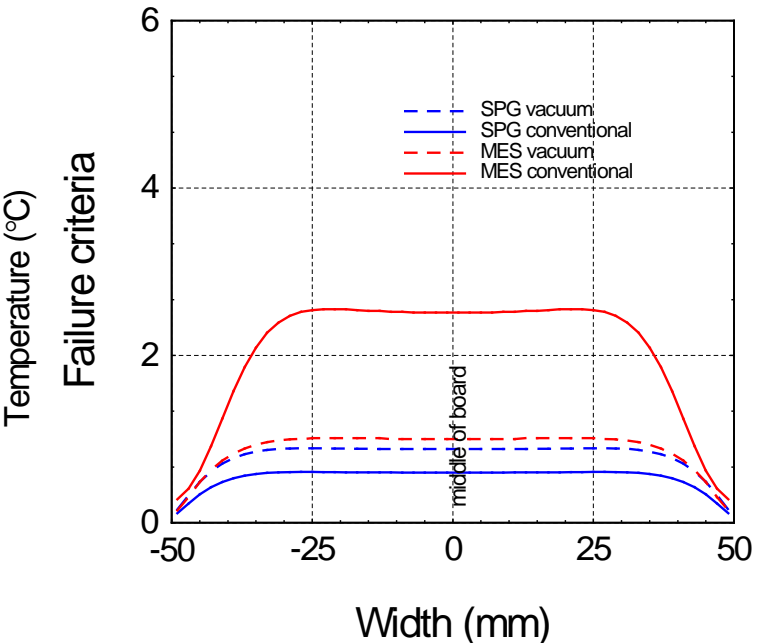

(b)

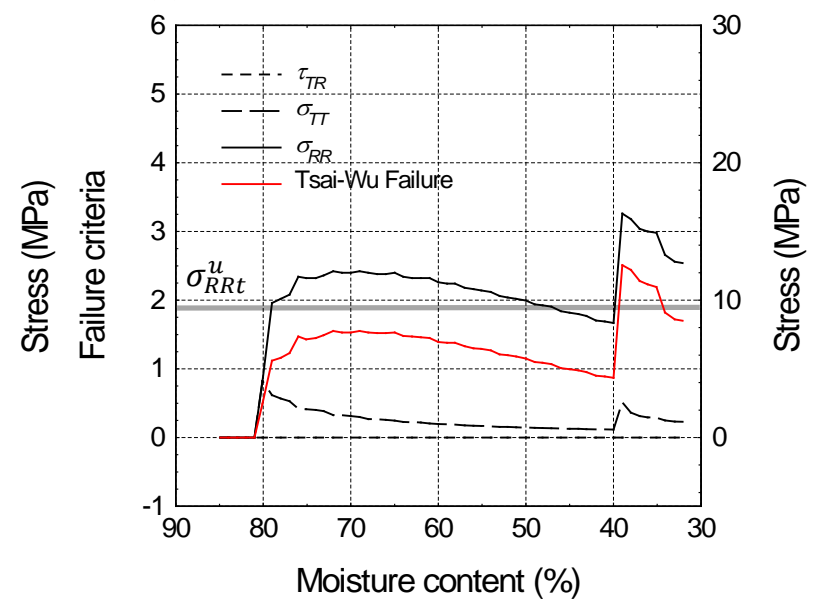

(d)

Fig 8. Tsai-Wu board surface check failure criteria versus moisture content during conventional and vacuum drying spotted gum and messmate (a). Tsai-Wu board surface check failure criteria profile in the width direction (board surface) at peak failure (b). MES = messmate, $S P G$ = spotted gum species. Tsai-Wu failure, normal stresses $\left(\sigma_{T T}, \sigma_{R R}\right)$ and shear stress $\left(\tau_{T R}\right)$ versus moisture content at the board end (c) and surface (d) for conventionally dried messmate. The grey line represents the ultimate tensile failure in the tangential direction $\left(\sigma_{T T t}^{u}\right)$ at the board end (c) and radial direction $\left(\sigma_{R R t}^{u}\right)$ at the board surface (d). 


\section{TABLES}

Table 1. Percentage of boards exhibiting drying stress-induced degrade for different species and drying types as reported by Redman et al (2017)

\begin{tabular}{ll|cccc}
\hline Species & Drying type & Collapse (\%) & Surface check (\%) & $\begin{array}{l}\text { Internal check } \\
\text { (\%) }\end{array}$ & $\begin{array}{l}\text { End split } \\
(\%)\end{array}$ \\
\hline \multirow{2}{*}{ spotted gum } & vacuum & 0 & 15 & 0 & 7 \\
& conventional & 0 & 17 & 0 & 11 \\
\hline \multirow{2}{*}{ jarrah } & vacuum & 0 & 7 & 8 & 6 \\
& conventional & 0 & 16 & 0 & 6 \\
\hline \multirow{2}{*}{ blackbutt } & vacuum & 0 & 30 & 0 & 64 \\
& conventional & 0 & 83 & 11 & 10 \\
\multirow{2}{*}{ messmate } & vacuum & 100 & 6 & 4 & 77 \\
& conventional & 100 & 29 & & 0 \\
\hline
\end{tabular}

$\mathrm{n}=100$

Table 2. Conventional and vacuum drying schedules used for spotted gum and messmate simulations expressed as temperature (Temp.) and relative humidity (RH)

\begin{tabular}{|c|c|c|c|c|c|c|c|c|}
\hline \multirow{3}{*}{$\begin{array}{c}\text { Moisture } \\
\text { content } \\
\text { change } \\
\text { point (\%) }\end{array}$} & \multicolumn{4}{|c|}{ spotted gum } & \multicolumn{4}{|c|}{ messmate } \\
\hline & \multicolumn{2}{|c|}{ Conventional } & \multicolumn{2}{|c|}{ Vacuum } & \multicolumn{2}{|c|}{ Conventional } & \multicolumn{2}{|c|}{ Vacuum } \\
\hline & $\begin{array}{c}\text { Temp. } \\
\left({ }^{\circ} \mathrm{C}\right)\end{array}$ & $\begin{array}{l}\text { RH } \\
(\%)\end{array}$ & $\begin{array}{c}\text { Temp. } \\
\left({ }^{\circ} \mathrm{C}\right)\end{array}$ & $\begin{array}{l}\mathrm{RH} \\
(\%)\end{array}$ & $\begin{array}{c}\text { Temp. } \\
\left({ }^{\circ} \mathrm{C}\right)\end{array}$ & $\begin{array}{l}\text { RH } \\
\text { (\%) }\end{array}$ & $\begin{array}{c}\text { Temp. } \\
\left({ }^{\circ} \mathrm{C}\right)\end{array}$ & $\begin{array}{l}\text { RH } \\
\text { (\%) }\end{array}$ \\
\hline$>70$ & 45 & 83 & 64 & 78 & 25 & 77 & 44 & 85 \\
\hline $70-60$ & 45 & 83 & 65 & 76 & 25 & 77 & 44 & 85 \\
\hline $60-50$ & 45 & 78 & 66 & 75 & 25 & 77 & 45 & 82 \\
\hline $50-40$ & 45 & 78 & 66 & 73 & 30 & 73 & 45 & 75 \\
\hline $40-35$ & 45 & 78 & 67 & 70 & 30 & 73 & 45 & 73 \\
\hline $35-30$ & 50 & 79 & 67 & 70 & 35 & 75 & 45 & 73 \\
\hline $30-25$ & 55 & 64 & 69 & 66 & 40 & 71 & 58 & 65 \\
\hline $25-20$ & 60 & 58 & 71 & 55 & 45 & 60 & 64 & 65 \\
\hline $20-15$ & 70 & 47 & 75 & 40 & 50 & 54 & 72 & 35 \\
\hline 15 - final & 70 & 35 & 80 & 55 & 55 & 40 & 80 & 55 \\
\hline
\end{tabular}

Table 3. Fibre saturation moisture content $\boldsymbol{X}_{f s p}$, air-dry density and elastic strain compliance-matrix input values at moisture content $\mathcal{X}$ : including Young's moduli E, shear moduli G and Poison's ratios (Redman et al., 2011, Guitard and El Amri, 1987). Below $\boldsymbol{X}_{\boldsymbol{f s p}}$ the propertied are calculated according to eq. (6).

\begin{tabular}{|c|c|c|c|c|c|c|c|c|c|c|c|c|c|c|c|}
\hline \multirow{2}{*}{ Species } & \multirow[b]{2}{*}{$x_{f s p}(\%)$} & \multirow{2}{*}{$\begin{array}{l}\text { Air-dry } \\
\text { density } \\
\left(\mathrm{kg} / \mathrm{m}^{3}\right)\end{array}$} & \multirow[b]{2}{*}{$X(\%)$} & \multicolumn{3}{|c|}{$\underline{\mathrm{E}(\mathrm{MPa})}$} & \multicolumn{3}{|c|}{$\underline{\mathrm{G}(\mathrm{MPa})}$} & \multicolumn{6}{|c|}{$\underline{\text { Poisson's ratios }}$} \\
\hline & & & & $E_{R}$ & $E_{T}$ & $E_{L}$ & $G_{R T}$ & $G_{L T}$ & $G_{L R}$ & $V_{R T}$ & $V_{R L}$ & $v_{T R}$ & $v_{T L}$ & $V_{L R}$ & $V_{L T}$ \\
\hline \multirow{2}{*}{ spotted gum } & \multirow{2}{*}{24.5} & \multirow{2}{*}{1010} & $\geq 24.5$ & 2,054 & 1,419 & 19,952 & 533 & 1,286 & 1,583 & \multirow{2}{*}{0.64} & \multirow{2}{*}{0.06} & \multirow{2}{*}{0.44} & \multirow{2}{*}{0.04} & \multirow{2}{*}{0.41} & \multirow{2}{*}{0.45} \\
\hline & & & 12 & 3,210 & 2,218 & 22,673 & 788 & 1,692 & 2,082 & & & & & & \\
\hline \multirow{2}{*}{ messmate } & \multirow{2}{*}{30.0} & \multirow{2}{*}{700} & $\geq 30.0$ & 1,003 & 608 & 13,683 & 241 & 744 & 949 & \multirow{2}{*}{0.66} & \multirow{2}{*}{0.06} & \multirow{2}{*}{0.44} & \multirow{2}{*}{0.04} & \multirow{2}{*}{0.39} & \multirow{2}{*}{0.45} \\
\hline & & & 12 & 2,180 & 1,321 & 16,687 & 468 & 1,163 & 1,483 & & & & & & \\
\hline
\end{tabular}


Table 4. Tension, compression and shear ultimate failure values in MPa for failure criteria calculations (Kretschmann, 2010)

\begin{tabular}{l|ccccccccc}
\hline Species & $\sigma_{T t}^{u}$ & $\sigma_{R t}^{u}$ & $\sigma_{L t}^{u}$ & $\sigma_{T c}^{u}$ & $\sigma_{R c}^{u}$ & $\sigma_{L c}^{u}$ & $\tau_{T R}^{u}$ & $\tau_{L T}^{u}$ & $\tau_{L R}^{u}$ \\
\hline spotted gum & 11.9 & 11.9 & 152.0 & 29.5 & 29.5 & 49.6 & 6.5 & 26.2 & 26.2 \\
messmate & 9.1 & 9.1 & 122.5 & 15.3 & 15.3 & 35.6 & 4.57 & 18.3 & 18.3 \\
\hline
\end{tabular}

